Author-produced version of the article published in International Journal of Life Cycle Assessment, 2018, №23(3), p. 492-506. The original publication is available at https://link.springer.com/article/10.1007\%2Fs11367-016-1226-2

Doi: 10.1007/s11367-016-1226-2

\title{
Extended community of peers and robustness of social LCA
}

\author{
Catherine Macombe, Denis Loeillet, Charles Gillet
}

C. Macombe, UMR ITAP, IRSTEA, 361 rue Jean-François Breton 34196 Montpellier, catherine.macombe@irstea.fr, tel : +33467046300, fax: +33499612436, corresponding author

D. Loeillet, UR GECO, CIRAD, TA B-26 / PS4. Boulevard de la Lironde. 34398 Montpellier Cedex 5, France

C. Gillet, CEP/ EpsilâHôm, Montpellier (France)

ñMathematics is just a means of conversion. The only thing that really matters is discussion of the premises and results (-). Under no circumstances can the complexity and scientific value of the deductions lend scientific value to the premises.ò (Maurice Allais)

\section{Introduction}

Life cycle analysis (LCA) methods have established their pedigree in the field of decision-making assistance, for handling increasingly complex situations (Hellweg and Mila i Canal, 2014) when environmental problems are involved. LCA is now the favoured family of methods for assessing various production activities throughout their life cycle, in terms of the potential environmental impacts of various alternatives.

\section{Awareness of weaknesses in LCA}

However, at the same time voices are being raised to criticize these methods for being insufficiently robust. LCA practitioners and researchers were the first to recognise and combat certain weaknesses, and are continuing their efforts to this day. Robustness was indeed one of the keywords at the 19th SETAC LCA Case Study Symposium, in Rome (11-13 November 2013). Practitioners and researchers created a SETAC-Europe LCA working group, which is developing a conceptual framework for modelling data uncertainties (Guo and Murphy, 2012).

Numerous weaknesses (bias, value judgements, uncertainties, etc.) have been listed (Huijbregts, 1998; Hofstetter et al., 2000). They compromise the robustness of the results, to the point of sometimes disagreeing with the classification of alternatives (Schaltegger, 1997; Lenzen, 2006). The ISO standard recommends conducting a critical review before circulating a study conducted by LCA for comparative purposes, to prevent manipulations or errors. It is recognised that if different LCA tools are employed, they give substantially different results, at least for certain local impacts (Dreyer et al., 2003; Pant et al., 2004). Aware of these weaknesses, Jolliet et al. (2010) consider that results relating to the same type of general damage (global warming, ozone layer depletion, etc.) for two life cycles are not significantly different when the difference between the values is less than $20 \%$. Our ignorance is so extensive that Hofstetter et al. (2000) proposed to design a proxy indicator known as ñuknown damageò. Due to these weaknesses, Heiskanen (2002) and Hellweg and Mila I Canals (2014) advise considering $L C A$ as a thought method, rather than a tool providing a single answer.

If we consider LCA as a thought method, overcoming uncertainties does not mean ñproviding a numerical result with the greatest possible precisionò. Rather, it involves adopting sufficiently relevant and accurate models representing reality (for example about the model of the system under study). These models must help uphold accurate reasoning appropriate to the submitted problem. 
Author-produced version of the article published in International Journal of Life Cycle Assessment, 2018, N²3(3), p. $492-506$. The original publication is available at https://link.springer.com/article/10.1007\%2Fs11367-016-1226-2

Doi: 10.1007/s11367-016-1226-2

\section{Weaknesses in SLCA}

While robustness is a recurrent concern in environmental life cycle analysis, the subject is no less crucial for social life cycle analysis (Macombe, 2013), though it has been less documented. To combat the biases associated with mathematical modelling of a pathway (a relationship which enables the impact assessment), Feschet et al. (2012), Macombe (2013) and Bocoum et al. (2015) propose two precautions: the first is to strictly limit the implementation of the pathway to its conditions of use defined above. The conditions of use, drawn from the literature, set the thresholds ${ }^{1}$ below or above which the model would lead to probably erroneous conclusions; the second is to interpret the results obtained exclusively by comparing at least two scenarios derived from the same reference state. Thus, there is a high probability of repeating the same biases in both calculations (generated by both scenarios). We can hope that the discrepancies between the results of the two calculations are significant, whereas the results of the calculation associated with a single scenario are seriously tarnished with errors. In other words, these authors refuse to practice in SLCA the equivalent of what is known as ñattributional LCAòin ELCA, out of concern precisely for robustness of the results. There too, the issue of uncertainties arises in terms of relevance and accuracy of models, more than in terms of numerical precision of the calculations.

Objective and subjective decisions to get out from uncertainties in LCA

Hofstetter et al. (2000) highlighted the existence of two types of uncertainties. Indeed, they explain that LCA methods suffer from uncertainties because of «the (unknown) system behaviour » and also because of «the uncertainty in value » (Hofstetter et al., 2000, page 161). Their approach has the merit of acknowledging the existence of «terra incognita» within any calculation made by LCA. Unfortunately, their solution assumes that there is one stable and identifiable «decision makersôvalue system » (idem, page 162). This hypothesis is far from gathering unanimity in social sciences. We assume that the Conventions theory (Batifoulier, 2001) will be helpful to clarify the issue. The Conventions approach differs from a values approach (like the Hofstettersône). The latter assumes that people are guided by stable values which give them firm preferences under all circumstances. The former asserts that people are capable of adopting conventions suited to such situations, and so switch convention depending on the problem. About uncertainties, the Conventions theory lays out the following ideas:

Implicitly, when handling the uncertainties in LCA, we act as if there were two sorts of decisions to get out from the uncertainties issue: ñobjectiveò decisions (such as implementing a Monte-Carlo simulation etc.) and ñsubjectiveò decisions (like taking into account the preferences of the backer). In the latter case only we recognise that they are associated with values and opinions. The Conventions theory asserts that the social world is built by people, so objectivity doesnâ exist, and there is no ñfairò decision in absolute terms. From the Conventions theory scope, people are capable of adopting conventions (agreements between members of a group) to define what is fair or not, depending on the problem. So, in the Conventions approach, there are no objective decisions. All the uncertainties relate to a convention. This means that all uncertainties are imperfections regarding a certain agreement about what is fair or not.

However, in the eyes of the players, the convention recognised in a given circle seems so natural that they most often do not realise that it is just one convention among other possible ones (Thévenot, 2002). Here is the case of the convention disturbed by uncertainties caused by ñthe (unknown) system behaviourò quoted by Hofstetter et al. (2000) Thus, they believe that the decisions made to surmount this type of uncertainties are ñobjectiveò.

Conversely, some other uncertainties are more challenging (Thévenot, 2002), as the famous ñuncertainty in valueò from Hofstetter et al. (2000). The players feel that ñit is a matter of opinionò. The latter cast doubt on the meaning of the situation, and undermine the legitimacy of the current

\footnotetext{
${ }^{1}$ For example, in the case of Prestonô pathway connecting added value generated and improving life expectancy, a condition will be that at least $60 \%$ of this added value be distributed in the form of direct and indirect remuneration.
} 
Author-produced version of the article published in International Journal of Life Cycle Assessment, 2018, №23(3), p. 492-506. The original publication is available at https://link.springer.com/article/10.1007\%2Fs11367-016-1226-2

Doi: 10.1007/s11367-016-1226-2

convention. Uncertainties which are a ñmatter of opinionò have the property of inviting the construction of another convention, in which the uncertainties can be lifted ${ }^{2}$ (Thévenot, 2002).

Certain environmental LCA practitioners share a convention on what is important in the LCA world. This convention is similar to the so-called industrial convention ${ }^{3}$ of Boltanski and Thévenot (1991). It values what is useful and effective, engineering and technology. Practitioners agree on the identification of chemical molecules, on the recognition of the laws of probability, on the calculations of the quantities of molecules emitted, etc. In general they perceive only the uncertainties which are natural in the industrial world (Thévenot, 2002), and in particular what can be expressed by figures. To reduce these uncertainties, they employ methods belonging to the same convention: error bands, data quality checking and identification, stochastic tests etc. Yet they do not always see the other sources of error.

Conversely, certain authors (e.g. Klöpffer, 1998; Hofstetter et al. 2000; Werner and Scholz, 2002) are aware of these problems, since they assert that the inventory phase cannot be conducted objectively. By denaturalising the implementation of the inventory, they express the idea that there are other possible conventions for conducting it.

Challenging uncertainty can no longer be disregarded when we tackle the ñimpact assessmentò step. There are so many choices to make that no-one can reasonably claim their objectivity. Certain authors, adopting the ñindustrial conventionò, attempt to control the questioning of the convention. Hofstetter et al. (2000) introduce categories of decision-makers (egalitarian, individualistic or hierarchic). Others (e.g. Mettier et al., 2006) create panels to investigate the preferences of stakeholders, or attempt to model the beliefs of the practitioner (Benetto et al., 2006). The attempt by Itsubo et al. (2012) to measure the preferences of Japanese society in terms of weighting factors of environmental impacts is another example of this.

New convention to get out from uncertainties in SLCA

There have also been attempts to incorporate social life cycle analysis into the industrial convention, by setting utilitarian ñareas of protectionò (Weidema, 2006) or by suggesting guidelines (UNEPSETAC, 2009) based on categories and lists. Those not settling for this are calling for another convention. They feel the need to justify the choice of indicators, i.e. to explicitly specify the convention chosen to handle the problem. In reality, the issue of uncertainties in LCA extends well beyond uncertainties handled by means of the industrial convention. The big debates raging across the field of LCA echo this confrontation, and the attempts to resolve them.

This paper questions the robustness of social LCA, based on four social LCA case studies. What are its weaknesses? How can they be combated? The solution suggested by the Conventions theory (Boltanski and Thévenot, 1991) consists in creating a new convention in each new situation.

To contribute to these debates, $(\& 2)$ we discuss the classification of weaknesses from Royâ decisionmaking assistance methods, when applied to LCA ;; (\&3) we discuss the literature about improving robustness thanks to peer participation; and (\&4) we analyse four case studies which we conducted in social LCA (with and without employing an extended community of peers); and lastly set out a discussion (\&5) and conclusions (\&6).

\section{Identifying the weaknesses of LCA}

\footnotetext{
${ }^{2}$ If we choose the commercial convention for example, the natural uncertainties will be lifted by knowledge of the prices and quality of the merchandise. Yet the critical uncertainties which could arise from equity of distribution of goods, or respect for natural beauty, will not be lifted without agreeing on another convention, possibly compromising with the commercial convention..

${ }^{3}$ The central values of this convention are usefulness and effectiveness.
} 
Author-produced version of the article published in International Journal of Life Cycle Assessment, 2018, №23(3), p. 492-506. The original publication is available at https://link.springer.com/article/10.1007\%2Fs11367-016-1226-2

Doi: 10.1007/s11367-016-1226-2

Bernard Roy belongs to the Paris-Dauphine LAMSADE laboratory. His research subject is robustness in the fields of operational research and decision-making. To be robust, methods must be able to withstand ñapproximations ${ }^{4}$ ò or ñzones of ignorance ${ }^{5}$ so so to preserve their prized properties (Roy, 2007). Robustness is a concern which must be involved a priori, upon formulating the problem. It ñshould be seen as a red thread throughout the modelling study starting from the very beginningò (Refsgaard et al., 2007, page 1543). That is why Roy says ñconcern for robustnessò rather than ñanalysisò, which could imply a posteriori handling.

With a view to decision-making assistance, concern for robustness means taking our ignorance into account. The approximations and zones of ignorance against which concern for robustness seeks to guard are points of weakness (Roy, 2005). We can tackle the points of weakness of a method from four viewpoints:

a) by how a lack of knowledge is handled: is it by neglecting it? By modelling it arbitrarily? Indeed, it may occur that the method doesnâ take into account its own shortage of knowledge.

b) by the questionable preferential meaning attributed to certain data. Sometimes, for instance quantifiable data, or data provided by one given source, are overestimated against qualitative data or data from all the sources. Thus, outputs are misleading.

c) by the modelling technique (especially in choice of parameters) used to take into account a complex aspect of reality. The modelling technique may provide a representation of reality which is so different from reality that the model becomes misleading.

d) by the presence of primarily technical parameters which have little or no specific meaning. These technical parameters entail a constraint in the calculation process which avoids the calculation to mirror reality by far.

(Roy, 2007).

The uncertainties may arise with regard to any of these four weakness points. So, we must deal with them.

Environmental LCA authors have clearly identified these four weakness points. For social LCA, the literature is less abundant. Nevertheless, we will highlight some examples of weaknesses directly drawn from the guidelines for Social Life Cycle Assessment of Products (UNEP-SETAC, 2009), referred to here as the ñGuidelinesò. In section 2, we leave to one side the other forms of social LCA being developed, while they come to the stage again in section 4 .

\subsection{Handling lack of knowledge}

In many LCA studies, lack of knowledge is neglected. Numerous authors have mentioned the errors caused by how the lack of knowledge is handled. Huijbregts (1998) mentions the uncertainties caused by ñunknown spatial and temporal variabilityò. Hofstetter et al. (2000) refer to ñepistemological uncertaintyò as the systematic lack of knowledge about nature and the future. The term ñepistemological uncertaintyò in von Bahr and Steen (2004), conversely, refers to the fact that ñthe system where the data is to be used (the unit process in question for the LCA) may differ from the system where the data was generated (the unit process recorded in the database)ò(von Bahr and Steen, 2004, page 369). Among the numerous causes of error listed by Lenzen (2006), several are associated with this first category: complexity of nature, lack of knowledge, prediction of future unknown effects, and episodic events.

All these causes of error are present in SLCA too, but some others are specific. Indeed, the Guidelines (page 44) advise classifying social/socio-economic subcategories by stakeholder categories because ñit can also ensure the comprehensiveness of the frameworkò. This sentence illustrates the illusion that there is no lack of knowledge in the framework provided by the Guidelines.

\subsection{Attributing a questionable preferential meaning to certain data}

\footnotetext{
${ }^{4}$ Approximation is an inaccurate representation while keeping a close link with the quantity or the object approximation stands for.

${ }^{5}$ The zones of ignorance are knowledge or experience shortage about one given domain.
} 
Author-produced version of the article published in International Journal of Life Cycle Assessment, 2018, №23(3), p. 492-506. The original publication is available at https://link.springer.com/article/10.1007\%2Fs11367-016-1226-2

Doi: 10.1007/s11367-016-1226-2

For instance, ñepisodic eventsò data are passed over in silence, because LCA mainly assesses the system based on routine operation. The preferential meaning attributed to certain data is among the causes of error stated by Lenzen (2006). Variability, even known variability, is often disregarded in favour of a so-called average state. It is the subjectivity of value judgements which alters the aggregation process according to Hofstetter et al. (2000), by attributing preferential meaning to certain data against the others. Similarly, Lenzen (2006) questions value judgements (uncertainty resulting out of imperfect preference measurements).

The preference for data from international norms is a major source of weakness in SLCA. As stated by the Guidelines (page 44) ñThe impact categories should preferably reflect internationally recognized categorizations/standardsé ò and again (page 48) ñInternational conventions are valuable instruments that have been negotiated by countries. They are the best example of a universal set of social criteriaò These conventions were imposed after the $2^{\text {nd }}$ World War by the combined power of the victors (Zolo, 2004). It is misleading to consider that they reflect agreement between balanced powers. For many issues (Jeorgensen et al., 2010; Ardvisson et al., 2015) the preference attributed to international conventions is misleading, and entails negligence of local context.

\subsection{Modelling arbitrarily}

Here is an example of arbitrary modelling. Very often, practitioners design the perimeter of the system by taking into account foreground only, without checking background. Thus, pieces of background might entail serious environmental impacts, and even more for social impacts. Huijbregts (1998) identifies modelling technique as a cause of uncertainty. In his editorial about the creation of an ñuncertaintiesò section in the International Journal of Life Cycle Assessment, Ciroth (2004) laments the uncertainties in the parameters of the LCA model, but also the uncertainties in the structure of the model, because of exaggerated simplification or even misconception of reality. Lenzen (2006) quotes inadequacy of models as a source of error.

The most radical questioning of the models can be found in the response by Schmidt and Weidema (2011) to the public consultation on a set of guidance documents of the International Reference Life Cycle Data System (ILCD) Handbook. The authors criticize the models commonly used in LCA: ñIn an attributional model, the main source of uncertainty is the bias introduced by the lack of accuracy in the method, i.e. that the average data and use of allocation leads to a result that does not reflect the actual consequences of the decision studiedò (page 3). Schmidt and Weidema (2011) advocate consequential modelling, which studies the probable consequences (including the socio-economic consequences) of the contemplated change on the rest of the economic activities. Hellweg and Mila I Canals (2014) recognise that nit is clear that for future-oriented decisions, it is desirable and sometimes essential to explicitly take into account the consequences of a change, including influences of the background economy and indirect effectsò (page 1113). These authors specify that ñconsequential modellingò also adds its share of uncertainties.

Hofstetter et al. (2000) also mention the hesitations to set the system boundaries fairly (thus truncating the system), stemming likely from an over simplification of reality, or from inadequacy of the models. Guo and Murphy (2012) demonstrate that choices of different temporal horizons can give opposing results.

Unfortunately, the Guidelines do not avoid arbitrary modelling; the reverse is the case. Here we are at the core of the blame aimed at SLCA. For instance, the Guidelines acknowledge that the consistency of the system cannot be scientifically defined (page 56) ñThe interconnected system of unit processes [-] depends first on the conceptualization-that is on the scope of the ideal system. [-] ñFive illustrations that help to clarify why different practitioners and studies can adopt different conceptions of the ideal system can be found in Annex 3 ò

Another example stems from splitting the SLCA study between a first ñinventory stepò and a second ñmpact assessment stepò. In short, this kind ${ }^{6}$ of modelling claims to respect the formal aspect of LCA, but in fact the inventory step gathers performances (not related to impacts), and the assessment step is empty.. So, the modelling proposed in the Guidelines is arbitrary.

\footnotetext{
${ }^{6}$ Another process is possible: to capture impacts first (Feschet et al., 2012) and then to turn back to the few data necessary to calculate the impacts.
} 
Author-produced version of the article published in International Journal of Life Cycle Assessment, 2018, N²3(3), p. $492-506$. The original publication is available at https://link.springer.com/article/10.1007\%2Fs11367-016-1226-2

Doi: 10.1007/s11367-016-1226-2

\subsection{Presence of technical parameters}

To give an example, the calculation of the magnitude of impacts in ELCA always includes the technical parameter «quantity of material» (data collected during inventory). This technical parameter has been built to evaluate global environmental impacts first. Thus, it is more than disabling in case of calculation of social impacts. Indeed, social impacts are seldom in proportion of the quantity of material.

The presence of essentially technical parameters with little or no specific meaning is a source of error rarely discussed by LCA authors. Certain practitioners probably fear distorting the method if they venture outside standard practices. For instance, using characterisation factors in the impact assessment phase is part of the formal LCA procedure. Nevertheless, the suggested factors are not always acceptable ${ }^{7}$ and introduce rigidity into the way of assessing impacts. The recent debate between Finkbeiner (2014) and Galatola and Pant (2014) regarding the ñtoxicityò aspect of environmental footprint ${ }^{8}$ (EF) illustrates this difficulty. The former advocates a canonical LCA procedure, which excludes the data from the ñisk assessmentò. The latter belong to the European Commission, and take the viewpoint of the decision makers. So they want to incorporate data on toxicity derived from the risk assessment. ñEven if toxicity aspects were taken out of the EF assessment (for example as kind of ñadditional environmental informationò based on comparative environmental risk assessment), they would eventually need to be reintegrated and weighted against the results of an EF assessment, in order to provide meaningful decision support.ò (Galatola and Pant, 2014, page 1359). Yet there are also authors who depart from technical parameters seeking inspiration, if not from the calculation methods, from the toxicity risk assessment (Demou, Hellweg and Hungerbühler, 2011).

The obstinate insistence of introducing the ñfunctional unitò (FU) ${ }^{9}$ parameter into SLCA in the Guidelines is another weakness. The concept of FU stems from the « functional analysis ». It allows to split the rendered services (and the impacts caused by the existence of these services) into units. The very concept of FU includes by its own the idea that the magnitude of the impacts caused by $n$ FU is $n$ times the magnitude of impacts caused by one FU alone. It means that each time we use the concept of FU, we assume that the relationship between quantity of FU and magnitude of impacts is linear! Indeed, as it is seldom the case in the real world (does freedom of trade unions depends on the number of shoes sold?) using the ñFUò technical parameter is misleading in some cases.

The causes of weakness identified by Roy have therefore been identified in environmental LCA. They are also present in social LCA. How can we lift, or at least manage, these causes of weakness in social life cycle analysis?

\section{Contributions of peers to LCA robustness}

As we have seen (\&1), various solutions have been proposed for resolving the weaknesses of LCA. These solutions are mainly within the dominant convention, the industrial convention. They manage one kind of uncertainties, but not all of them. As we will see, the recommended solution is to create a new convention, which presupposes introducing new rationales and new players. Yet the industrial convention refrains from consulting players other than engineers (to caricature) because it goes against the quest for standardisation (Basson and Petrie, 2007) ${ }^{10}$.

\footnotetext{
${ }^{7}$ Huijbregts et al. (2000) however wondered about the sources of uncertainty in calculating toxicity potentials (a quantitative representation of potential impacts per unit emission of a toxic substance), and conclude that they may still suffer from large uncertainties

${ }^{8} \mathrm{EF}$ is presented as the future consensual method of environmental life cycle analysis of the European Commission.

${ }^{9}$ Other Social LCA methods (Macombe, 2013) include relating of impacts to FU.

${ }^{10}$ The attempt to encode the values of the stakeholders ñmay well be the effect of a call for greater standardisation of LCA methodology (where this pertains to value-laden aspects) and a drive towards endpoint
} 
Author-produced version of the article published in International Journal of Life Cycle Assessment, 2018, №23(3), p. 492-506. The original publication is available at https://link.springer.com/article/10.1007\%2Fs11367-016-1226-2

Doi: 10.1007/s11367-016-1226-2

If these constraints can be overcome, is there a means of improving SLCA robustness by constructing a new convention, and how do we go about it? We discuss how to create a new convention (\& 3.1) and highlight the contribution of Funtowicz and Ravetz (1991), and then present the benefits expected from the formation of an extended community of peers (\& 3.2).

\subsection{How to construct a new convention?}

Within the Conventions theory, Thévenot (1993) specifies that there are local conventions (for instance one convention within a group of farmers which explains the right way of farming in a particular location; or one convention within the inhabitants of one given town, which explains the behaviour which enhance the reputation of the town, etc.). A local convention specifies what is valuable locally, and how to behave as a result. Here we will look at this type of convention. In practice, the description of the construction of local conventions merges with the recommendations of Funtowicz and Ravetz (1991) in situation of ñpost-normal scienceò.

Indeed, although they do not employ the term ñconventionsò Funtowicz and Ravetz mean ñconventionsò. These authors recognise the plurality of legitimate perspectives and call for ñmutual respect among various perspectives and forms of knowingò (Funtowicz and Ravetz, 1994, page 1882). ñWhen science is applied to policy issues, the conflicting values in any decision process cannot be ignoredò (page 1181). These authors talk about ñvaluesò (see introduction section). We assert that they actually mean conventions, for two reasons: these ñvaluesò supposedly evolve through exchanges, and the advantage of these ñlegitimate perspectivesò is to decide what should be done. All the same, conventions are beliefs which have the property to evolve through exchanges, and these beliefs shape legitimate perspectives to decide what should be done.

The initial problem raised by Funtowicz and Ravetz is a decision making context ñwhere system uncertainties ${ }^{11}$ or decisions stakes (or both) are high.ò (Funtowicz and Ravetz, 1994, page 1884). Indisputably, this is the case with most works in SLCA. These authors specify that we are ñmoving to a science based on unpredictability, incomplete control, and a plurality of legitimate perspectives.òthat they call ñpost-normal scienceò (Funtowicz and Ravetz, 1994, page 1881). In the new scientific outlook, uncertainties are managed (not eliminated) and values are made explicit (rather than assumed).

The solution recommended by Funtowicz and Ravetz (1991) is to associate an ñextended community of peersò with the scientists. We suggest that the initial role of this community will be to construct a compromise ${ }^{12}$ between the present conventions, in order to make the necessary axiological (value) choices. Indeed, failing that, various parts of the model could be constructed using incompatible conventions. The second role is to bring the model closer into line with reality. ñExperts are becoming aware of the insoluble question of what, if anything, their model has to do with the real world outside, since their outputs are generally untestableò (Funtowicz and Ravetz, 1994, page 1884). Every noncompliance between the formal representation (e.g. by LCA) and reality is extremely disruptive (Roy, 2007).

The construction of the new convention involves promoting dialogue between peers and researchers/consultants/investigators, in which each takes ownership of the subject and sincerely wants to resolve the problem. To achieve this result, we need to correctly identify the future peers, and then get them interested, so that they take ownership of the problem. As Akrich et al. (1988a) assert with regard to innovations, ñthe fate of a project depends [-] on the alliances it allows and on the interests that it mobilises.ò (page 17).

Peers are identifiable by their influence on the problem. Differentiation of the stakeholders is described by Mitchell, Agle and Wood (1997). The variety of peers which will form the ñextended

modelling which denies stakeholders an opportunity to explore their values and preferences and examine the effects of these on the decisions to be madeò (Basson and Petrie, 2007, page 175).

${ }^{11}$ The term ñsystem uncertaintiesòmeans that the problem is not the discovery of one fact, but the comprehension or management of a reality.

${ }^{12}$ Because this is a compromise between conventions, it will ñmanageò uncertainties, without being able to eliminate them. 
Author-produced version of the article published in International Journal of Life Cycle Assessment, 2018, №23(3), p. 492-506. The original publication is available at https://link.springer.com/article/10.1007\%2Fs11367-016-1226-2

Doi: 10.1007/s11367-016-1226-2

communityò advocated by Funtowicz and Ravetz, however, is less extended than that of the stakeholders. In fact the peers are only the persons, among the stakeholders, who agree to dedicate time to the problem, and so who are directly interested. Only those who identify big stakes for themselves will commit to the study.

How to get the peers interested? Though based on different research issues, the works of three authors converge. Ray Hilborn (1979) analysed the reasons for failures and successes in terms of application of systems analysis to ecological systems. Shepherd and Bowler (1997) are concerned with improving participation in environmental impact assessment, and Henry Mintzberg (1980) explores the reasons which make decision makers refrain from using the simulation models which supposedly provide them with decision-making assistance. In summary, for participation to be effective, it is necessary i) for the participants to get the power to influence the decision making process; ii) for a large amount of time to be devoted to communication; iii) for the techniques to be understandable and transparent; iv) to avoid focusing on tools, and focus on the end.

These considerations mean that the extended community of peers must be formed and involved from the start of the process.

\subsection{What does an extended community of peers offer?}

There are project analyses on the extent of peer involvement. Van der Sluijs (2002) mentions the following benefits: ñextended quality control through broad public participation, which increases the acceptability of the process and its outcomesò. Refsgaard et al. (2007) set out five arguments to substantiate the improvement of policies discussed by peers. Stakeholder participation improves - so they say - the quality of the problem formulation and questions addressed; provides personal observations/insights that lead to new focuses for empirical research addressing dimensions of the problem that were overlooked or underexposed by the professionals; contributes to increasing the expertise on local conditions and societal values that adds to the existing expertise; criticizes the assumptions made by the professionals, which leads to changes towards assumptions that better match real-life conditions; and generates creative thinking on mechanisms through which various scenarios may affect different sectors of society.

Beierle (2002) conducted a meta-analysis (239 cases) of case studies relating to environmental choices. He shows that the community of peers improves the quality of decisions made, that it increases joint gains, provides new ideas, useful analysis and new information, and improves access to scientific information and expertise. Conversely, we cannot draw conclusions on cost-effectiveness.

Bijlsma et al. (2007) assert that peer participation improves factual accuracy of knowledge, and improves the robustness of the policy decided. The authors report on a trial conducted on the same catchment area, with the same initial information, by a group of experts on the one hand, and by an extended peer group on the other. From the problem framing phase (which defines the issue), major differences appeared: the experts posed the problem in terms of quantity of water; the others in terms of water quantity and quality. The community of peers took into account new scenarios, considered a larger spatial scope, and suggested different technical solutions. These differences are due to different ways of managing uncertainties in the two groups (Bijlsma et al., 2011).

Introducing an extended community of peers changes how the study proceeds, and modifies its results. Does the same apply to problems involving a social life cycle analysis?

\section{Effects of the extended community of peers in social LCA}

To determine whether the creation of an extended community of peers influences the weakness points identified by Roy, we will analyse four case studies (social LCA) which we conducted in 2011, 2012 and 2013. The first ones were conducted in Southern territories, relating to various agricultural products (banana, meat, orange). For the ñbananaò case, the change assessed was the switch from certain aerial phytosanitary treatments (by plane) to terrestrial treatments. For the ñmeatò and ñorangeò cases, the sponsors wanted to assess the social effects which might result from the development of 
Author-produced version of the article published in International Journal of Life Cycle Assessment, 2018, №23(3), p. 492-506. The original publication is available at https://link.springer.com/article/10.1007\%2Fs11367-016-1226-2

Doi: 10.1007/s11367-016-1226-2

local production (to the detriment of imports), over the entire life cycle. The other case study comes from a Northern region, with the objective of comparing local supply systems and large scale supply chains of various agricultural products. A priori, the problems studied were high-stakes, involving stakeholders bearing potentially conflicting visions. The situations were very characteristic of postmodern science (Funtowicz and Ravetz, 1994).

In two studies (banana, orange), a community of peers was formed from the start of the project, while in the two others (meat, short/long circuits), no real community of peers was formed. Of course, the idea should be qualified; the situation is never quite so clear. If we had 200 case studies, we could qualify the involvement of the players over a continuum ranging from: ño buy-in at allò to ñcomplete commitment by all the playersò. Yet we only have four case studies, which we believe show great contrast in terms of player commitment.

Here we are assuming that the extended community of peers was involved, as soon as it was in evidence (both in sharing knowledge and in the choice of options for conducting the study), beyond managing the LCA assessment tools. Involvement may originate from any other individual interested in the project, including scientists, consultants or sponsors. In the banana and orange cases, the industry professionals and State administrative personnel participated fully in the study (proactively, and in response to wide-ranging surveys). In the other cases, there were obstacles opposing full participation by the peers: either the peers maintained ideological positions not compliant with the reality on the ground, or they did not get involved beyond lobbying to obtain subsidies. We will return to this subject in section 5.2.

In all these case studies, the search for future social effects was guided by the Multiple Capital Model, which was described in Gillet and Loeillet (2013), and of which the consultant had a good command. The consultant sought to assess in advance the effects of a change, based on various means (literature, technical \& economic surveys, interviews, extrapolations of financial calculations etc.). The life cycle was constructed from an added value chain (Porter, 1985) which set out the links of all kinds between the suppliers and a central firm, to which chain the usage step was added. All the case studies were conducted directly by the same consultant.

For the first two case studies presented, we will illustrate how the extended community of peers contributed solutions, in terms of 1) lack of knowledge; 2) data with preferential meaning; 3) modelling, in the sense of Roy. However, we did not find any peer involvement in the fourth weakness identified by Roy, which is ñ the presence of primarily technical parameters which have little or no specific meaningò That is why we will not cover this last weakness.

\section{1-When the community of peers buys into the project}

\section{Banana case}

The community of peers brought together the producer groups, exporter groups, the national and local administrations (agricultural and veterinary services), as well as agricultural outreach services, crop science researchers specialised in production, and the consultant. All the players directly concerned were present at the steering committees, and took part in the information exchange and the construction of the results, with varying degrees of involvement.

The problem being addressed was that of changing the mode of phytosanitary treatment.

Lack of knowledge: The community of peers contributed with new elements to address the lack of information. For example, a usually central parameter in all assessment models is the quantity produced by the plantation. Yet here, in half the cases, the farmers were not achieving maximum production. Their behaviour seemed irrational, but discussions between peers provided the explanation. Two phenomena justified this particularity: a quota system (whereby the farmer received $100 \%$ subsidies if they produced $70 \%$ or $80 \%$ of their individual quota, and this aid decreased if they produced more), and the regular occurrence of cyclones (which void individual quotas). Various 
Author-produced version of the article published in International Journal of Life Cycle Assessment, 2018, №23(3), p. 492-506. The original publication is available at https://link.springer.com/article/10.1007\%2Fs11367-016-1226-2

Doi: 10.1007/s11367-016-1226-2

strategies were in play on the ground: one plantation sought to reach $80 \%$ and no more, to obtain the best margin; another reduced its phytosanitary treatments (i.e. costs and production); a third (often small-scale) produced as much as possible and exceeded its quota, aiming for as high a revenue as possible. Every farmer, depending on their own situation, tried to optimise their production level between their yield capacities, the cyclone season, the damage caused by diseases and the quota system. In this jungle of confusion, only the community of peers could clarify the various situations.

Preferential Meaning: Before the beginning of the study, professionals attributed a preferential meaning to the new costs (of labour and equipment) caused by the adoption of terrestrial treatment methods (which often require more frequent treatments), at the expense of aerial treatments. The reasoning developed to consider the consequences of the change lamented this additional cost. Thanks to exchanges on practices, and to facts debated jointly, it emerged that the additional cost was not systematic $^{13}$, and above all, that other data needed to be incorporated into the reasoning (including the health of the pesticide sprayers).

Modelling: The community of peers also made it possible to select the right parameters to develop the various phytosanitary treatment models to evaluate. The crop scientists described the various possible treatment systems, with modifications of the accompanying technical itineraries. An in-depth examination of the agricultural techniques was required, as the example of the adapted fallowing method shows. The banana study raised the issue of the most relevant fallowing process ${ }^{14}$ to study in terms of its socio-economic consequences. There are actually several fallowing methods, which influence the overall duration of the banana cycle. There were no statistics available, and field practices varied greatly. One option needed to be chosen. It was the peers (in this case under the influence of crop scientists) who made this choice ( $1 / 3$ ha fallow on the farm per 1 ha of bananas), selecting the most practical and safest technique for the farmers.

In the ñbananaò case, the original convention was that nothing must be changed, at the risk of seeing production disappear! The usual practices had to be maintained, including aerial treatments. At the end of the exchange process, the community of peers acknowledged that some changes could be managed. They could anticipate them to forestall any harmful effects arising. It became important to work together to find solutions. So the community of peers worked in such a way that three weaknesses detected by Roy could in large part be lifted (table 1).

Table 1 here

\section{Orange case}

The community of peers brought together the national and local administrations, farmersô representatives and a SICA (agricultural trading company) marketing oranges (though achieving poor sales), and the consultant. It should be noted that the participants thought that the local industry was practically non-existent! In fact, there were very large quantities of oranges imported into the territory. They wanted to promote the development of a native orange production industry, based on the existing industry, though not structured, to reduce imports of this fruit.

Lack of knowledge: In reality, the orange industry was very important socially and economically for the less well-off families of the island, and for some big landowners who wanted to harness previously underexploited land. The exchanges within the community of peers revealed this. In the social analysis method employed, one step consisted in calculating the portion of added-value obtained by each link

\footnotetext{
${ }^{13}$ The study showed that other techniques (defoliation) were effective, without endangering the financial balance of the farm.

${ }^{14}$ Fallow is an unharvested crop grown between two harvested crops demanding in terms of fertiliser, which allows the soil to rest and regain nutrients. Its duration varies (from a few months to a few years) depending on the condition of the soil, the main crops, etc.
} 
of the value chain. Usually, this calculation is done by applying well-known ratios, applicable to numerous industries. In the case of the orange, this calculation proved that the industry was not viable for the farmers. It could not exist! The usual added-value calculation parameters had no meaning here.. The oranges were apparently sold via a SICA, but the sale price to the SICA was too low for production to be profitable. In reality, the most important industry for the local orange was the unofficial one. There were orange trees growing in small ñwildò orchards (often less than 1/2 ha), without receiving any particular care. The ripe oranges $\ddot{i}$ un calibrated and untreated - were collected by the families and sold from the field side (at a price $30 \%$ higher than the sale price to the SICA). Thanks to the peers, it was possible to reconstruct the actual value-chain.

Data with preferential meaning: At the beginning of the study, the players focused on organising the local orange industry in the form of producer groups, and on securing subsidies in order to ensure its viability. The joint discovery by the active industries showed that other factors prevailed (family labour, farm size, etc.), depending on the industry type. In addition, these neglected industries provided a large number of families with a living.

Modelling: Thanks to the information provided by the peers, researchers produced 4 orange industry models with different configurations. The models react differently to the scenarios contemplated: for example, the ñgreeningò disease in oranges, in the process of emerging on the territory, would have a different effect on productivity within these 4 models.

In the ñorangeò case, the majority of the players shared a simple convention - ñwhat really provides value are the industries organised by the cooperatives; they are what need to be subsidisedò before finally recognising the new convention: ñthere are family type informal industries which work very well, and it is legitimate to help them.ò

By working together, the extended community of peers managed to mitigate three weaknesses (table 2).

Table 2 here

In both these cases, a community of peers was set up to lead the project. It shared information and provided a fairly fine description of the system to anticipate probable impacts, and even enable forecasts about the system $\hat{Q}$ reaction to various events.

\section{2-Without a community of peers}

\section{Local supply systems/large scale supply chains}

The project steering committee did not set up a community of peers. The requested objective was to perform comparison of local supply systems with large scale supply chains, in terms of social and economic results for farmers.

To compare the short and long circuits, the agricultural products to be studied first needed to be chosen, in the absence of local data. The project steering committee chose several products based on national figures, but was unable to obtain an opinion on how they matched the reality in the region. Some of the chosen industries proved unsuitable for comparison. Indeed, locally, the chosen vegetables existed only in the ñlarge scale supply chainò version or in the ñocal supply systemò version, but not in both.

The project also aimed to compare two types of livestock farming, this time very much present in the same region. Unfortunately, the contrasting economic and social results of these two modes of livestock farming could not be attributed to the nature of the supply (local or large scale). Indeed, local supply livestock farming has other characteristics which distinguish it from large scale supply chain livestock farming. For example, feeds are produced on the farm, from their own cereals. The involvement of peers aware of this particularity would have been able to adjust the weight of the ñsale 
Author-produced version of the article published in International Journal of Life Cycle Assessment, 2018, №23(3), p. 492-506. The original publication is available at https://link.springer.com/article/10.1007\%2Fs11367-016-1226-2

Doi: 10.1007/s11367-016-1226-2

circuit typeò datum in the interpretation of the results. The results of this case in terms of weaknesses are reported in table 3 .

\section{$\underline{\text { Table } 3 \text { here }}$}

\section{ñMeatò case}

The study steering committee did not want to team up with other players. The issue was to compare importing meat with the development of local production. Unfortunately, the local industry was nonexistent, and could only expand through massive imports of livestock feed, breeding stock and other inputs which cannot be produced locally.

All the players stuck to the same stereotypical language. They had commissioned a previous study, which counted the number jobs potentially created by the development of the industry. Although this study was inconsistent (the jobs losses count was missing, and feed imports were not taken into account), the players used it to claim subsidies. In addition, the initial field surveys showed that the small producers were neglected by the industry, though it used them as a ñshowcaseò to claim agricultural aid.

In this extreme case, the study was rapidly suspended (table 4). It actually emerged that the players collaborating in the project were not seeking to communicate their knowledge.

\section{Table 4 here}

We cannot draw a general conclusion from such a small number of cases (table 5). However, both case studies where a real community of peers was formed provided opportunities to mitigate the weaknesses of the SLCA method, thanks to the design of one new convention. Moreover, they provided much more satisfactory results for all (including for the sponsors and researchers) than those where no community of peers was mobilised. In particular, a relevant and plausible impact assessment was provided in the former two cases, while this was impossible in the latter two.

\section{Table 5 here}

\section{5- Discussion}

These experiences now bring us to discuss how the community of peers works ( $\& 5.1)$, but also the limits of use of the community of peers (\& 5.2). These limits highlight the role of the researchers/consultants leading the case study in ensuring that the community of peers is working correctly (\& 5.3).

\subsection{How does the community of peers work?}

The community of peers works by constructing a new convention based on diversity. The creation of a new convention can be described by the ñnterest modelò proposed by Akrich et al. (1988b) (here the new convention is considered an innovation). In this model, the players develop the convention, work it and adapt it in line with their own centres of interest (Akrich et al., 1988a, 1988b). Collective construction within the extended community inevitably brings about adaptations of LCA method on the table at the outset of the process.

The variety ${ }^{15}$ of values among the community of peers is an important factor for success, because we can infer that great differences are based on differences in knowledge. And the more varied the knowledge among the peers, the more debate and efforts it will generate, and the closer it will bring the formal model into line with reality. The existence of divergent values is a sign that people are

\footnotetext{
${ }^{15}$ ñWhere LCA is used to support decision making, provision for diversity with regard to value-laden aspects is thus requiredò(Basson and Petrie, 2007, page 175)
} 
Author-produced version of the article published in International Journal of Life Cycle Assessment, 2018, №23(3), p. 492-506. The original publication is available at https://link.springer.com/article/10.1007\%2Fs11367-016-1226-2

Doi: 10.1007/s11367-016-1226-2

constructing their world view on different conventions. The choice and stabilisation (i.e. solidity) of the convention constructed for the study thus, paradoxically, requires the greatest initial variety of opinions. It is the dynamic of the compromise itself which forces each individual to explicitly specify what counts, and therefore constructs ñjustifiable actionsò A justifiable action is an action on which a convention can be anchored, because a general judgement is involved in the decision which led to this action (Thévenot, 2002). Peers stop debating a subject only when there has been a justifiable action on this subject satisfactory to them all. By coming to agreement on appraisal of the justifiable action, they create the ad hoc convention which acts as its medium.

Bringing together people all referring a priori to the same convention (which is often the ñindustrial conventionò in a committee of experts in the same field) leads to blindly following a non-explicit and therefore unjustified convention, which would be called into question by the first outside participant, whereas a convention developed from justifiable actions originating from players bearing divergent conventions possesses greater robustness and stability.

\subsection{The limits of peer involvement.}

Of course, peer involvement is not the ultimate weapon against the weaknesses of social LCA, as we have discovered for ourselves. In our experience, we encountered a variety of scenarios.

\section{The elusive community of peers}

It may be impossible to create a community of peers. In the study on meat, the official aim was to compare the merits of local meat production with those of imported meat. Yet the people willing to provide information were part of an organised lobby group. Their testimony complied with a restricted set of communication materials issued by the lobby group, and above all manipulated the figures with a view to obtaining subsidies. Their rationale was that every euro spent promoting local production would encourage local activities (farming, slaughter, etc.). Yet their plan did not reduce the amount of imports, nor of the subsidies to local production. In accordance with the life cycle philosophy, the consultant showed them that the real problem was either importing meat, or importing livestock feed, tractors, inputs, etc. to enable so-called ñocal productionò to exist. Once the problem had been reformulated in these terms, the professionals refused to participate.

\section{The players may not come to agreement}

Many problems encountered in the comparison of local/large scale supply chain would never have arisen if the players had been able to get along. The local elected officials dreamt of designing and creating local organic agriculture supply for local canteens and markets, in a region long dedicated to intensive agriculture. The Regional Chamber for Agriculture (which was in addition part of the political opposition) asserted that these local supply chains, and especially the organic industries, were not structured on the ground. They could not get along or reach any compromises. Note that the study did not raise any vital stakes for the elected officials, who took the view that they had time to define their strategy. The study at least enabled them to get to know the industries in their territory.

\section{The community of peers may come to agreementé on false ideas.}

Conversely, for the administration and banana professionals, the study involved very high stakes, with the survival of the industry in play. Yet they also bore their share of false ideas. They believed that switching from aerial treatment to terrestrial treatment would be a cataclysm for all types of banana farms. They believed that the cost of treatment for all would soar. After a survey, this fear proved to be justified only for some medium farms, and above all the big farms. In fact, terrestrial treatment was already being implemented, either in aerial treatment exclusion zones, or alongside aerial treatments. Hence the operators already had the appropriate equipment. On the other hand, the plantation labourers refused to apply these treatments, because they had to wear heavy protective equipment which was very uncomfortable in this climate. Consequently, on the small and medium farms, the bosses carried out this task themselves, so their work time was not counted. Hence the additional cost of the treatment itself, over a few hectares, remained insignificant. However on the large farms, the bosses hired temporary workers who only applied the ground treatment. Besides these practices endangering the health of the temporary workers, the additional cost was very high for these large 
Author-produced version of the article published in International Journal of Life Cycle Assessment, 2018, №23(3), p. 492-506. The original publication is available at https://link.springer.com/article/10.1007\%2Fs11367-016-1226-2

Doi: 10.1007/s11367-016-1226-2

plantations, which lacked the resilience of the small ones. The industry professionals shared a received idea, which proved unfounded.

\section{Power imbalance and manipulation}

The formation of communities of peers ñfollow the new standard-making virtues of inclusiveness and consensus and base their legitimacy on their claim of balanced representation of, and participation by, all categories of stakeholders.ò (Cheyns and Riisgaard, 2014). Even if we manage to include a wide variety of people, and even if they come to agreement on a new convention, we need to be aware that there are still two major obstacles to success. There are persistent power imbalances between individuals, which prevent them from expressing themselves as peers accurately, as Cheyns highlighted for small producers in the Round Table on sustainable oil palm (Cheyns, 2014). Peers are also standard bearers for a cause. They are approached by multiple lobby groups, which try to influence them. Certain ñsmallò producers, whose sincerity cannot be placed in doubt, are orchestrated by other categories of player.

\section{Introduction of new uncertainties}

The formation of a community of peers introduces or reinforces new uncertainties, which Bijlsma et al. (2011) call strategic and institutional uncertainties. Strategic uncertainty refers to a lack of knowledge about how players will respond to each other $\hat{\mathbf{Q}}$ actions. The players will perceive the risks and opportunities differently. Institutional uncertainty is the result of players belonging to different multiple policy arenas (Bijlsma et al., 2011). However, the community of peers contributes to the robustness of the method by managing uncertainty, which refers to the lack of knowledge about the substance of the policy problem.

\section{$5.3 \quad$ Role of researchers/consultants}

We might be discouraged in the face of these observations. The creation of a community of peers does not guarantee that problems will be solved. Creating an extended community of peers does not mean that everyonêิ role is equivalent. The consultants or researchers leading the study have a particular responsibility.

The first is to clarify what the evaluative question is, i.e. the specific problem that the players wish to highlight via the study commissioned. In fact, most of the time, the sponsors themselves have not clearly determined the scope of the study, or what specifically they are seeking to know. This was the case in the four studies presented above. In general, there are several issues mixed in the spontaneous requested aim. The point is to extract one or more clear questions, which can be answered, taking into account the resources mobilised.

The second responsibility of the study leaders is to rapidly distinguish situations (illegal competition agreements, lobbying focused exclusively on seeking subsidies, permanently unbalanced power games) where it will probably be impossible to construct an operational community of peers. It is actually a waste of time to continue working under these conditions. The sponsors must be made aware of this as early as possible.

The situation is favourable when the sponsors accept expansion of the community of peers based on the project. The community often shares unfounded beliefs, or its members cannot agree on essential representations. Here the study leaders have the responsibility to move the situation forward. They shall apply themselves to decrypting the power games and in revealing unfounded beliefs, even if they are shared by all their partners. They need to resort to ñdata triangulationò (Thiétart et coll., 1999). Hence in the study quoted above, the partners were certain that the average yield of the banana plantations was 50 tonnes per hectare. A survey by the Directorate of Agriculture would prove to them that it was actually 32 tonnes per hectare. The consultants often perform a consistency and relevance check on peer declarations (Gillet and Loeillet, 2013), the objective of which is precisely to smoke out those which should be re-examined. By dint of all these precautions, it will be possible, at least in part, to remedy the weaknesses of the study conducted. The main thing is to obtain sufficiently relevant and correct models to aid the thought process.

Because of these particular responsibilities, the study leaders are not on the same level as the other peers. They do not represent a financial backer, as in the case of an audit. Within an assessment, the 
Author-produced version of the article published in International Journal of Life Cycle Assessment, 2018, №23(3), p. 492-506. The original publication is available at https://link.springer.com/article/10.1007\%2Fs11367-016-1226-2

Doi: 10.1007/s11367-016-1226-2

point is to assess the social consequences of change, based on facts and thanks to the good will of all parties. The study leaders have this threefold role of generating the evaluative question, providing verified facts and facilitating dialogue.

Forming an extended community of peers is very time consuming and demands a lot of effort. The time to be dedicated to communication has been estimated at $3 / 4$ of the project time (Hilborn, 1979). To prevent failure, the communication needs to be appropriate, transparent and high-level (Geurts and Joldersma, 2001). All these efforts are fruitless in many cases. Yet when the study contributes to a sensitive subject, as Funtowicz and Ravetz (1991) reported, forming a community of peers becomes essential.

\section{6- Conclusions}

True, there are problems with the robustness of social LCA, similar to those encountered by environmental LCA. There is no objective decision making, it is all a matter of conventions. In practice, to cope with uncertainties, the players distinguish ñobjectiveò decisions and subjective decisions. In the ñindustrialò convention to which the LCAs (both environmental and social) belong, certain uncertainties can be lifted by means of mathematics. However, this uncertainty-restricted treatment omits other uncertainties, which it is truly essential to address in order to improve the robustness of LCA methods. The four weaknesses revealed by Roy are the real obstacles to the robustness of LCAs. To deal with these weaknesses, must we follow the advice of Funtowicz and Ravetz, and form an extended community of peers?

We believe that we can draw a number of lessons from the four social LCA case studies presented. In the two cases where the formation of a community of operational peers failed, all the weaknesses suggested by Roy are present. At the extreme, the study becomes impossible to conduct. By contrast, in the two cases where an operational community of peers was formed, some of the weaknesses could be mitigated. In addition, these four cases highlighted the playersô games preventing things from working properly. Some of the playersôgames (lobbying, illegal competition agreements...) lead to failure, while other situations (difficulty in finding a consensus, a priori false representations...) are manageable. To this end we would like to highlight the role assigned to the study leader(s). Their involvement (defining the evaluative question, providing facts, negotiating, etc.) is essential in ensuring the ñworkabilityò of the community of peers.

When questioning the robustness of social LCA, we inevitably stumble across the big debates shaking the field of LCA: directly applying data from a database to a case study, accurately defining the system boundaries, choice of model (consequential or attributional) etc. Actually, concealed behind the issue of robustness is a question mark over the scientific status of the ñlife cycleò method. In our world (Science), the legitimacy of the method is dependent on this. So it seems that there is a paradox: introducing an extended community of peers increases robustness, while reducing the genericity of the method. Indeed, does the practice of LCA not lose its chances of acquiring scientific status if each LCA study appoints an ad hoc community of peers, i.e. a different one in each case?

We might actually assume that the results of the LCA will be all the less reproducible when guided by the choices of a community of peers, a priori unforeseeable. In reality, the scientism of the approach is not based on the choice of the same convention, whatever the study undertaken. It is based on the implementation of the same rigorous approach leading the peers to choose the convention applicable in the specific case (Mathé, 2014). Specifying which convention was chosen to conduct the study does not impair the genericity of the method. On the contrary, the researcher $\mathbf{a}$ critique of their own methods is an integral part of the scientific approach (Lakatos, 1994). It is a prerequisite for incorporating social LCA in a scientific approach. 
Author-produced version of the article published in International Journal of Life Cycle Assessment, 2018, №23(3), p. 492-506. The original publication is available at https://link.springer.com/article/10.1007\%2Fs11367-016-1226-2

Doi: 10.1007/s11367-016-1226-2

Acknowledgments: C. Macombe is member of ELSA research group. We thank the colleagues for their advices.

\section{References}

Akrich M., Callon M., Latour B. (1988a) A quoi tient le succès des innovations ? part 1 : Lârt de lântéressement, ANN MINES, 11, 4-17.

Akrich M., Callon M., Latour B. (1988b) A quoi tient le succès des innovations ? part $2:$ Le choix des porte-parole, ANN MINES, 12, 14-29.

Ardvisson R., Baumann H. , Hildenbrand J. (2015) On the scientific justification of the use of working hours, child labour and property rights in social life cycle assessment: Three topical reviews, INT J LIFE CYCLE ASS, Vol. 20 (2015), 2, p. 161-173.

Basson L., Petrie J.G. (2007) An integrated approach for the consideration of uncertainty in decision making supported by Life Cycle Assessment, ENVIRON MODELL SOFTW, 22, 167-176.

Batifoulier P. (2001) Théorie des Conventions, Economica, Paris.

Benetto E., Dujet C., Rousseaux P. (2006), Possibility theory: a new approach to uncertainty analysis? INT J LIFE CYCLE ASS, 11 (2), 114-116.

Beierle T.C. (2002) The quality of stakeholder-based decisions, RISK ANAL, 22, 739-749. Doi: $10.1111 / 0272-4332.00065$.

Bijlsma R.M., Wolters H.A., de Kok J.L., Hoekstra A.Y. R. (2007) "A methodology to determine the contribution of stakeholders to the robustness of environmental policy decisions." International Conference on Adaptive \& Integrated Water Management, Coping with complexity and Uncertainty. http://www. newater. uni-osnabrueck. de/caiwa/data/papers\% 20session G. Vol. 3. 2007.

Bijlsma, R.M., Bots P.W.G., Wolters H.A., Hoekstra A.Y. (2011) An empirical analysis of stakeholdersôinfluence on policy development: the role of uncertainty handling. ECOL SOC 16(1): 51. [online] URL: http://www.ecologyandsociety.org/vol16/iss1/art51

Boltanski L. Thévenot L. (1991) De la Justification-Les Economies de la Grandeur, nrf essais, Gallimard, Paris.

Cheyns E. (2014) Making ñminority voicesò heard in transnational roundtables: the role of local NGOs in reintroducing justice and attachments, Agric Human Values, DOI 10. 1007/s10460-0149505-7

Cheyns E., Riisgaard L. (2014) Introduction to the symposium : The exercise of power through multistakeholder initiatives for sustainable agriculture and its inclusion and exclusion outcomes, Agric Human Values, DOI 10.1007/s10460-014-9508-4

Ciroth A. (2004) Uncertainties in life cycle assessment, INT J LIFE CYCLE ASS , 9 (3), 141-142.

Demou E., Hellweg S., Hungerbühler K, 2011, An occupational chemical priority list for future life cycle assessments, J CLEAN PROD, 19, 1339-1346. 
Author-produced version of the article published in International Journal of Life Cycle Assessment, 2018, №23(3), p. 492-506. The original publication is available at https://link.springer.com/article/10.1007\%2Fs11367-016-1226-2

Doi: 10.1007/s11367-016-1226-2

Dreyer L. C. , Niemann A. L., Hauschild M.Z. 2003 Comparison of three different LCIA methods: EDIP97, CML2001 and Eco-indicator 99. Does it matter which one you choose', INT J LIFE CYCLE ASS, vol 8, pp. 191-200.

Finkbeiner M. (2014) Product environmental footprint-breakthrough or breakdown for policy implementation of life cycle assessment? INT J LIFE CYCLE ASS, 19:266-271, DOI $10.1007 / \mathrm{s} 11367-013-0678-\mathrm{x}$

Funtowicz, S.O., Ravetz J.R. (1991) A New Scientific Methodology for Global Environmental Issues, In Costanza R. (ed.) Ecological Economics: The Science and Management of Sustainability, Columbia University Press, New York, 137 152.

Funtowicz, S.O., Ravetz J.R. (1994) Uncertainty, complexity and post-normal science, ENVIRON TOXICOL CHEM, 13 (12), 1881-1885.

Galatola M., Pant R. (2014) Reply to the editorial ñProduct environmental footprint-breakthrough or breakdown for policy implementation of life cycle assessment?ò written by Prof. Finkbeiner (Int J Life Cycle Assess 19(2): 266-271), INT J LIFE CYCLE ASS, 19: 1356-1360, DOI 10.1007/s11367-0140740-3

Geurts J. and Joldersma C. (2001) Methodology for participatory policy analysis, EUR J OPER RES, $128,300-310$.

Gillet C., Loeillet D. (2013) Social life cycle value chain analysis practices, chapter 6, in Macombe (coord.) Social LCAs, Socio-economic effects in value chains, Théma- FruiTrop, CIRAD, Montpellier, 120-139.

Guo M., Murphy R.J. (2012) LCA data quality: sensitivity and uncertainty analysis, SCI TOTAL ENVIRON, 435-436, 230-243

Heiskanen E. (2002) The institutional logic of life-cycle thinking, J CLEAN PROD, 10, 427-437.

Hellweg S., Milà I Canals L. (2014) Emerging approaches, challenges and opportunities in life cycle assessment, SCIENCE, 344, 1109-1113, DOI: 10.1126/science.1248361

Hilborn R. (1979) Some failures and successes in applying systems analysis to ecological systems, J APPL SYST ANAL, vol 6, 25-31.

Hofstetter P., Baumgartner T., Scholz R.W. (2000) Modelling the valuesphere and the Ecosphere: Integrating the Decision Makers Perspectives into LCA, INT J LIFE CYCLE ASS, 5 (3) 161-175.

Huijbregts M.A.J. (1998) Application of uncertainties and variability in LCA. Part II: Dealing with parameter uncertainty and uncertainty due to choices in life cycle assessment, INT J LIFE CYCLE ASS, 3(6) 343-351.

Huijbregts M.A.J., Thissen U., Jager T., van de Meent D., Ragas A.M.J. (2000) Priority assessment of toxic substances in life cycle assessment. Part II: assessing parameter uncertainty and human variability in the calculation of toxicity potentials, CHEMOSPHERE, 41, 575-588.

Itsubo N., Sakagami M., Kuriyama K., Inaba A. (2012) Statistical analysis for the development of national average weighting factors-visualization of the variability between each individual $\hat{\Theta}$ environmental thoughts, INT J LIFE CYCLE ASS, 17, 488-498.

Jeorgensen A., Lai L.C.H., Hauschild M. ( 2010) Assessing the validity of impact pathways for child labour and well-being in social life cycle assessment, INT J LIFE CYCLE ASS, 15: 5-16. 
Author-produced version of the article published in International Journal of Life Cycle Assessment, 2018, №23(3), p. 492-506. The original publication is available at https://link.springer.com/article/10.1007\%2Fs11367-016-1226-2

Doi: 10.1007/s11367-016-1226-2

Jolliet O., Saade M., Crettaz P. (2010) Analyse du Cycle de Vie : comprendre et réaliser un écobilan. Les presses polytechniques et universitaires romandes, Lausanne, Suisse.

Klöpffer W. (1998) Subjective is not arbitrary, INT J LIFE CYCLE ASS, 3 (2) 61.

Lakatos I. (1994) Histoire et méthodologie des sciences, Collection Bibliothèque dôhistoire des sciences, Presses Universitaires de France, Paris.

Lenzen M. (2006) Uncertainty in impact and externality assessments, implications for decisionmaking, INT J LIFE CYCLE ASS, 11(3), 189-199.

Macombe C. (coord.) (2013) Social LCAs, Socio-economic effects in value chains, Théma- FruiTrop, CIRAD, Montpellier.

Mathé S. (2014) Integrating participatory approach in social life cycle assessment: the SLCA participatory approach, INT J LIFE CYCLE ASS, 19, 1506-1514.

Mettier T., Scholz R.W., Tietje O. (2006) Measuring preferences on environmental damages in LCIA. Part 1: Cognitive limits in panel surveys, INT J LIFE CYCLE ASS, 11(6), 394-402

Mintzberg H. (1980) Beyond implementation: an analysis to the resistance to policy analysis, INFOR, vol 18, n², May 1980, 100-138.

Mitchell R.K., Agle B.R., Wood D.J. (1997) Toward a Theory of Stakeholder Identification and Salience: Defining the Principle of Who and What Really Counts, ACAD MANAGE REV, 22 (4), 853-886.

Pant R., van Hoof G., Schowanek D., Feijtel T., de Koning A.,Hauschild M., Pennington D., Olsen S.I., Rosenbaum R., (2004). Comparison between three different LCIA methods for aquatic ecotoxicity and a product environmental risk assessment. INT J LIFE CYCLE ASS, 9(5), 295-306.

Porter M. E. (1985) Competitive advantage: creating and sustaining a superior performance, Free Press, New York

Refsgaard J.C., van der Sluijs J.P., Højberg A. L., Vanrolleghem P.A. (2007) Uncertainty in the environmental modelling process, ENVIRON MODELL SOFTW , 22 (2007) 1543-1556.

Roy B. (2005) A propos de robustesse en recherche opérationnelle et aide à la décision, in : Billaut J.C., Moukrim A., Sanlaville E. (sous la direction de) «Flexibilité et robustesse en ordonnancement », Lavoisier, Paris.

Roy B. (2007) La robustesse en recherché opérationnelle et aide à la décision: une préoccupation multi facettes, Annales du LAMSADE n 7, ñRobustness in OR-DAò, Université Paris-Dauphine, 209-235

Schmidt, J. H., Weidema, B. (2011). Response to the public consultation on a set of guidance documents of the International Reference Life Cycle Data System (ILCD) Handbook, 2.-0 LCA consultants.

Shepherd A., Bowler C. (1997) Beyond the requirements: improving public participation in EIA, J ENVIRON PLANN MAN, 40 (6) pp 725-738.

Schaltegger S. (1997) Economics of life cycle assessment: inefficiency of the present approach, BUS STRAT ENVIRON, vol 6, 1-8. 
Author-produced version of the article published in International Journal of Life Cycle Assessment, 2018, №23(3), p. 492-506. The original publication is available at https://link.springer.com/article/10.1007\%2Fs11367-016-1226-2

Doi: 10.1007/s11367-016-1226-2

Thévenot L. (2002) Conventions of co-ordination and the framing of uncertainties, in Fullbrook E. (ed.) Intersubjectivity in Economics, London, Routledge, 181-197

Thévenot L. (1993) A quoi convient la théorie des conventions ? Réseaux n62, p 137-142.

Thiétart R.-C. et coll. (1999) Méthodes de recherche en management, Dunod, Paris.

UNEP-SETAC (2009) Guidelines for social life cycle assessment, United Nations.

Von Bahr B., Steen B. (2004) Reducing epistemological uncertainty in life cycle inventory, J CLEAN PROD, 12, 369-388.

Van der Sluijs J.P. (2002) A way out of the credibility crisis of models used in integrated environmental assessment, FUTURES, 34, 133-146.

Weidema B. (2006) The Integration of Economic and Social Aspects in Life Cycle Impact Assessment, INT J LIFE CYCLE ASS, special issue, 11(0): 89-96.

Werner F., Scholz R.W. (2002) Ambiguities in Decision-Oriented Life Cycle Inventories: The role of mental models, INT J LIFE CYCLE ASS, 7(6), 330-338.

Zolo D. (2004) Globalizzazione, Una mappa dei problemi, GLF Editori Laterza, Roma-Bari.

$\underline{\text { List of tables }}$

\begin{tabular}{|l|l|l|l|}
\hline & 1) lack of knowledge & $\begin{array}{l}\text { 2) data with preferential } \\
\text { meaning }\end{array}$ & 3) modelling \\
\hline $\begin{array}{l}\text { Weaknesses before } \\
\text { construction of the } \\
\text { community of peers }\end{array}$ & $\begin{array}{l}\text { Players think that the } \\
\text { yield is the main } \\
\text { factor to be taken } \\
\text { into account }\end{array}$ & $\begin{array}{l}\text { layers think that the } \\
\text { principal impact of the } \\
\text { change is the huge } \\
\text { additional cost for } \\
\text { terrestrial treatment }\end{array}$ & $\begin{array}{l}\text { Players think only aerial } \\
\text { treatment is viable. The } \\
\text { sector will die if they } \\
\text { switch to terrestrial } \\
\text { treatment }\end{array}$ \\
\hline $\begin{array}{l}\text { Solutions brought by the } \\
\text { community of peers }\end{array}$ & $\begin{array}{l}\text { The target yield per } \\
\text { ha is variable } \\
\text { depending on the } \\
\text { strategy of the } \\
\text { farmer }\end{array}$ & $\begin{array}{l}\text { layers design the other } \\
\text { important factors to be } \\
\text { considered (worker } \\
\text { exposure to pesticides, } \\
\text { farm typology...) }\end{array}$ & $\begin{array}{l}\text { Players design together } \\
\text { the different practical } \\
\text { treatment models to be } \\
\text { assessed }\end{array}$ \\
\hline
\end{tabular}

Table 1: Examples of Weaknesses and Solutions brought by the community of peers in the ñoananaò case

\begin{tabular}{|l|l|l|l|}
\hline & 1) lack of knowledge & $\begin{array}{l}\text { 2) data with preferential } \\
\text { meaning }\end{array}$ & 3) modelling \\
\hline $\begin{array}{l}\text { Weaknesses before the } \\
\text { construction of } \begin{array}{c}\text { Players think that } \\
\text { community of peers }\end{array}\end{array}$ & $\begin{array}{l}\text { Organizing local } \\
\text { there is no local } \\
\text { orange value-chain }\end{array}$ & $\begin{array}{l}\text { A socio-economical } \\
\text { subsidies is the key } \\
\text { model for orange value- } \\
\text { chain to be designed } \\
\text { (producer groups-based } \\
\text { industry) }\end{array}$ \\
\hline Solutions brought by the & Players discover that & There are several key & Players describe the \\
\hline
\end{tabular}


Author-produced version of the article published in International Journal of Life Cycle Assessment, 2018, N²3(3), p. $492-506$. The original publication is available at https://link.springer.com/article/10.1007\%2Fs11367-016-1226-2

Doi: 10.1007/s11367-016-1226-2

community of peers

\begin{tabular}{|c|c|c|}
\hline $\begin{array}{l}\text { there is an important } \\
\text { orange informal } \\
\text { value-chain }\end{array}$ & $\begin{array}{l}\text { factors to be assessed, } \\
\text { depending on the type of } \\
\text { the current value-chains }\end{array}$ & $\begin{array}{l}\text { four actual socio- } \\
\text { economic models for } \\
\text { orange local production }\end{array}$ \\
\hline
\end{tabular}

Table 2: Examples of Weaknesses and Solutions brought by the community of peers in the ñorangeò case

\begin{tabular}{|c|c|c|c|}
\hline & 1) lack of knowledge & $\begin{array}{l}\text { 2) data with preferential } \\
\text { meaning }\end{array}$ & 3) modelling \\
\hline $\begin{array}{l}\text { Weaknesses in the } \\
\text { absence of the } \\
\text { community of peers }\end{array}$ & $\begin{array}{l}\text { Steering } \quad \text { committee } \\
\text { chooses certain } \\
\text { products which is } \\
\text { lacking a local or large } \\
\text { scale value-chain }\end{array}$ & $\begin{array}{l}\text { Steering committee } \\
\text { thinks that the } \\
\text { profitability of the pig } \\
\text { farming stems from its } \\
\text { short circuit outlet, } \\
\text { despite the cause being } \\
\text { the origin of the pig feed } \\
\text { (self-produced on the } \\
\text { farm). }\end{array}$ & / \\
\hline What happened? & $\begin{array}{l}\text { It was impossible to } \\
\text { perform a comparison } \\
\text { for the products above. }\end{array}$ & $\begin{array}{l}\text { Backers were reluctant } \\
\text { to account for the origin } \\
\text { of the pig feed. }\end{array}$ & $\begin{array}{l}\text { Modelling } \\
\text { performed by the } \\
\text { consultant alone, } \\
\text { without interactions } \\
\text { with other players. }\end{array}$ \\
\hline
\end{tabular}

Table 3: Examples of Weaknesses in the ñlocal/large scaleò case

\begin{tabular}{|l|l|l|l|}
\hline & 1) lack of knowledge & $\begin{array}{l}\text { 2) Data with preferential } \\
\text { meaning }\end{array}$ & 3) modelling \\
\hline $\begin{array}{l}\text { Weaknesses in the } \\
\text { absence of } \\
\text { community of peers }\end{array}$ & $\begin{array}{l}\text { Steering committee } \\
\text { did not want to share } \\
\text { their knowledge }\end{array}$ & $\begin{array}{l}\text { Steering committee } \\
\text { focused on the result of } \\
\text { the ñjobs studyò only }\end{array}$ & / \\
\hline What happened? & $\begin{array}{l}\text { The study was not } \\
\text { disseminated. The players did not want } \\
\text { reports were expunged } \\
\text { of the most } \\
\text { inconvenient findings } \\
\text { and conclusions. }\end{array}$ & $\begin{array}{l}\text { The modelling possible, } \\
\text { to recognise that there } \\
\text { were other data to take } \\
\text { into account }\end{array}$ & \\
\hline
\end{tabular}

Table 4: Examples of Weaknesses in the ñmeatòcase

\begin{tabular}{|l|l|l|l|l|}
\hline $\begin{array}{l}\text { Name of case } \\
\text { study }\end{array}$ & $\begin{array}{l}\text { Peers community } \\
\text { construction? }\end{array}$ & \multicolumn{4}{|l|}{ Did the players deal with weaknesses of the SLCA study? } \\
\hline & $\begin{array}{l}\text { 1) lack of } \\
\text { knowledge }\end{array}$ & $\begin{array}{l}\text { 2) data with } \\
\text { preferential } \\
\text { meaning }\end{array}$ & $\begin{array}{l}\text { 3) Modelling } \\
\text { technique }\end{array}$ \\
\hline Banana & full & yes & yes & yes \\
\hline Orange & full & yes & yes & yes \\
\hline $\begin{array}{l}\text { local/large scale } \\
\text { supply }\end{array}$ & no & no & no & $/$ \\
\hline
\end{tabular}


Author-produced version of the article published in International Journal of Life Cycle Assessment, 2018, N²3(3), p. $492-506$. The original publication is available at https://link.springer.com/article/10.1007\%2Fs11367-016-1226-2

Doi: 10.1007/s11367-016-1226-2

\begin{tabular}{|l|l|l|l|} 
Meat & opposition & no & no
\end{tabular}

Table 5: Overview of the four case studies regarding mitigation of weaknesses in SLCA 